\title{
HUBUNGAN POLA ASUH ORANGTUA DENGAN PERILAKU SEKSUAL REMAJA
}

\author{
PARTY RELATIONSHIP ASUH PARENTS WITH SEXUAL ADOLESCENT \\ BEHAVIOR
}

\section{Rosnancy Renolita Sinaga}

Universitas Surya Nusantara

Email: rosnancy.sinaga@suryanusantara.ac.id

\begin{abstract}
ABSTRAK
Pendahuluan: Semakin meningkatnya perilaku seksual yang dilakukan oleh remaja dari tahun ke tahun dan hal tersebut berkaitan dengan pola asuh yang diterapkan oleh orangtua sebagai pendidik pertama dalam keluarga. Dalam penelitian ini identifikasi masalah yang pertama adalah bagaimana gambaran pola asuh orangtua, yang kedua adalah bagaimana gambaran perilaku seksual remaja, dan yang ketiga adalah hubungan pola asuh orangtua dengan perilaku seksual remaja. Tujuan: Penelitian ini bertujuan untuk mengidentifikasi hubungan pola asuh orangtua dengan perilaku seksual remaja. Metode: Penelitian ini menggunakan metode deskriptif. Metode penelitian menggunakan pendekatan dengan desain deskriptif kuantitatif. Populasi dalam penelitian ini adalah siswa Sekolah Menengah Atas Advent Martoba Pematangsiantar yang dengan sampel berjumlah 81 orang. Instrumen yang digunakan dalam penelitian ini berupa kuesioner dan data diolah menggunakan rumus dan rentang skala Likert. Hasil: Didapati pola asuh demokratis $91 \%$, pola asuh permisif $67,7 \%$, pola asuh otoriter $69 \%$, adanya hubungan yang signifikan antara pola asuh orangtua dengan perilaku seksual remaja dengan hasil sig (2-tailed) 0,000. Korelasi Pearson $-0,861>r(0,5)$ maka korelasinya antara pola asuh orang tua dengan perilaku seksual remaja signifikan dan korelasi tidak searah, hubungan pola asuh orangtua dengan perilaku seksual remaja adalah kuat. Saran diberikan kepada orangtua agar menyadari pentingnya pola asuh terutama dalam perilaku seksual remaja; kepada remaja agar dapat mempertahankan perilaku yang baik mengenai perilaku seksual. Diskusi: Disarankan agar penelitian ini dapat digunakan sebagai referensi penelitian yang lebih luas, meneliti faktor yang lebih kompleks dengan populasi yang lebih besar.
\end{abstract}

Kata Kunci: pola asuh orangtua, perilaku seksual, remaja

\begin{abstract}
Introduction: Increasing sexual behavior committed by juveniles from year to year and it is related to parenting applied by parents as the first educators in the family. In this study, the identification of the first issue is how the image of parenting parents, the second is how the image of adolescent sexual behavior, and the third is the parent parenting relationship with sexual behavior teens. Purpose: This study aims to identify the relationship parenting parents with sexual behavior teens. The method used in this research is descriptive method. Method: The research method used approach with descriptive quantitative design. The population in this research is high school students Advent Martoba Pematangsiantar who with the sample amounted to 81 people. Instruments used in this study in the form of questionnaires and data processed using the formula and Likert scale range. Result: The democratic parenting found $91 \%$, $67.7 \%$ permissive parenting, authoritarian parenting 69\%, a significant relationship between parenting parents with adolescent sexual behavior with results sig (2-tailed) 0.000. Pearson Correlation $-0.861>r(0.5)$ the correlation between parenting parents with adolescent sexual behavior is significant and the correlation is not unidirectional, relationship parenting parents with adolescent sexual behavior is powerful. Advice given to parents to realize the importance of parenting especially in teenage sexual behavior; to adolescents in order to maintain good behavior regarding sexual behavior.
\end{abstract}

SKOLASTIK KEPERAWATAN

Vol, 4, No. 1 Januari - Juni 2018

ISSN: $2443-0935$ E-ISSN $2443-1699$ 
Discussion: Suggested that this study can be used as a reference of a broader research, examining factors are more complex with a larger population.

Keywords: parenting, sexual behavior, adolescence

\section{PENDAHULUAN}

Remaja adalah generasi penerus bangsa yang sangat berperan penting dalam proses kemajuan bangsa. Namun jika remaja tidak dipersiapkan dengan baik maka mereka akan menjadi masalah bagi negara. Pada era modern ini, banyak masalah-masalah yang dihadapi oleh remaja terkait perkembangan zaman dengan masuknya budaya barat

ke Indonesia. Masalah seksual merupakan satu hal yang sudah tidak asing lagi dikalangan remaja. Sehingga perbincangan mengenai masalah seksual sangat melekat dengan remaja terkait perilaku remaja saat ini dalam hal perilaku seksual yang dilakukan tanpa adanya hubungan pernikahan. Pergeseran norma baik-buruk, benar-salah, terutama dalam konteks seksualitas semakin jelas terlihat.

Pergeseran norma yang terjadi dipengaruhi oleh banyak faktor, namun faktor yang sangat mempengaruhi terjadinya pergeseran norma tersebut adalah keluarga karena keluarga adalah tempat pertama dimana individu dibentuk. Keluarga merupakan lembaga sosialisasi primer pertama bagi seorang individu, dimana setiap individu pertama kali mendapatkan pendidikan mengenai berbagai hal termasuk pendidikan nilai, norma, ataupun pendidikan agama adalah melalui adanya keluarga terutama orang tua. Dalam hal ini sangat berkaitan erat pula dengan pola asuh yang diterapkan oleh para orang tua dari masing-masing keluarga. Keluarga yang mempunyai anak pada usia remaja harus sangat hati-hati dalam menerapkan pola asuh terutama dalam hal seksual. Karena dimasa remaja terjadi perubahan-perubahan fisik, psikis, dan kematangan fungsi seksual atau sering disebut masa pra-pubertas dan masa pubertas.

Masa pra-pubertas dan pubertas sebenarnya itu penuh dengan titik-titik kritis dan banyak kesulitan. Sehingga usaha bimbingan dan pendidikan bagi anak-anak puber itu jadi berat, sulit, dan memerlukan kebijaksanaan (Kartono, 2007). Pada masa pubertas ini juga remaja lebih rentan terhadap masalah seksual, karena remaja yang sedang dalam periode ingin tahu dan ingin mencoba, akan meniru apa yang dilihat atau didengar dari pergaulan, teman maupun media massa karena pada umumnya mereka belum pernah mengetahui masalah seksual secara lengkap dari orang tuanya. Di sinilah peran orang tua sangat dibutuhkan untuk dapat memberikan pendidikan seks yang baik kepada anak dan melakukan komunikasi yang terbuka mengenai hal ini. Namun kenyataannya banyak orang tua yang menganggap pendidikan seks pada anak merupakan hal yang tabu, sehingga jarang sekali pendidikan seks tersebut diterapkan dalam sebuah keluarga. Ketika hal tersebut terjadi, maka remaja cenderung akan mencari tahu melalui sumber lain diantaranya melalui teman-temannya ataupun melalui berbagai media cetak dan elektronik. Media ini dapat diakses siapa saja dan kapan saja 
sehingga dapat mengakibatkan salah pengertian dan menjerumuskan remaja pada perilaku seks bebas yang tidak sesuai dengan norma budaya ketimuran.

Salah satu faktor masalah seksualitas pada remaja terjadi perubahan-perubahan hormonal yang meningkat hasrat seksual (libido seksualitas) remaja. Peningkatan hasrat seksual ini membutuhkan penyaluran dalam bentuk tingkah laku tertentu. Penyaluran itu tidak dapat segera dilakukan karena adanya penundaan usia perkawinan. Selanjutnya remaja akan berkembang lebih jauh terhadap hasrat seksual kepada tingkah laku yang lain seperti berciuman dan masturbasi. Kecenderungan semakin meningkat oleh karena adanya penyebaran informasi dan rangsangan seksual melalui media massa yang dengan adanya teknologi canggih (video cassette, fotokopi, satelit, VCD, telepon genggam, internet dan lain-lain) menjadi tidak terbendungnya lagi yang sedang dalam periode ingin tahu dan ingin mencoba tindakan perilaku seksual (Sarwono, 2011).

Kecenderungan perilaku seksual yang buruk dewasa ini salah satunya dipengaruhi oleh pola asuh orang tua yang salah dalam membesarkan remaja (Djiwandono, 2008). Banyak orangtua tidak memberikan informasi mengenai seks dan kesehatan reproduksi kepada anaknya, karena takut tersebut justru akan meningkatkan terjadinya hubungan seks bebas di kalangan remaja. Orangtua juga beranggapan bahwa seks merupakan hal yang tak perlu untuk dibicarakan. Pendidikan seks yang kurang menyebabkan anak mencari informasi di luar yang justru dapat menjerumuskan dan merugikan mereka sendiri. Remaja mendapatkan informasi tentang seks dari buku atau majalah porno berkisar $63,2 \%$, menonton film biru berkisar $46,7 \%$ dan masturbasi berkisar 30,2\% (data BKKBN, 2009)

Di wilayah Asia Tenggara, menurut WHO 2011 memperkirakan 4,2 juta aborsi dilakukan setiap tahun, dan sekitar 750.000 sampai 1,5 juta terjadi di Indonesia, dimana 2.500 di antaranya berakhir dengan kematian, angka aborsi di Indonesia diperkirakan mencapai 2,3 juta pertahun. Sekitar 750.000 diantaranya dilakukan oleh remaja. Setiap tahun telah terjadi 1,5 juta kasus aborsi di Amerika Serikat, ratusan ribu di negara-negara Eropa, dan lebih dari 2 juta di kawasan Asia. Di Jepang, sejak 1972, tercatat ratarata 1,5 juta kasus aborsi setiap tahun. Dengan mengacu pada angka-angka tersebut, setiap tahun sedikitnya tercatat 40 sampai 60 juta kasus aborsi di seluruh dunia (WHO, 2011).

Berdasarkan hasil Survei Demografi Kesehatan Indonesia 2012 komponen Kesehatan Reproduksi Remaja (SDKI 2012 KRR), bahwa secara nasional terjadi peningkatan angka remaja yang pernah melakukan hubungan seksual pranikah dibandingkan dengan data hasil Survei Kesehatan Reproduksi Remaja Indonesia (SKRRI, 2007). Hasil survei SDKI 2012 KRR menunjukkan bahwa sekitar 9,3\% atau sekitar 3,7 juta remaja menyatakan pernah melakukan hubungan seksual pranikah, sedangkan hasil SKRRI 2007 hanya sekitar $7 \%$ atau sekitar 3 juta remaja. Sehingga selama periode tahun 2007 sampai 2012 terjadi peningkatan kasus remaja yang pernah melakukan hubungan seksual sebanyak 2,3\% (SKRRI 2012 KKR). 
Meningkatnya perilaku seksual di kalangan remaja diperkuat oleh data Kementerian Kesehatan (Kemenkes, 2009) dari penelitian di empat kota. Sebanyak 35,9 persen remaja punya teman yang sudah pernah melakukan hubungan seksual sebelum menikah, bahkan 6,9 persen responden telah melakukan hubungan seksual.

Remaja usia 15-19 tahun baik putra maupun putri tidak sedikit yang sudah pernah melakukan hubungan seksual. Data terhadap 10.833 remaja laki-laki berusia 15-19 tahun didapatkan sekitar 72 persen sudah berpacaran, 92 persen sudah pernah berciuman, 62 persen sudah pernah meraba-raba pasangan dan sekitar 10,2 persen sudah pernah melakukan hubungan seksual. Sedangkan hasil survei dari 9.344 remaja putri yang berusia 15-19 tahun didapatkan data sekitar 77 persen sudah berpacaran, 92 persen sudah pernah berciuman, 62 persen sudah pernah meraba-raba pasangan dan 6,3 persen sudah pernah melakukan hubungan seksual (Ahli Komisi Perlindungan Anak, 2007 dalam Arub 2017).

Hasil kajian Badan Koordinasi Keluarga Berencana Nasional (BKKBN) pada tahun 2010 diperoleh rata-rata dari 100 remaja di wilayah Jabodetabek, sekitar 54\% pernah melakukan hubungan seksual pranikah. Rata-rata serupa juga terjadi di sejumlah kota besar lainnya. Tercatat rata-rata kejadian seks pranikah di Surabaya mencapai $47 \%$ sedangkan di Bandung dan Medan 52\%. Rentang usia remaja yang pernah melakukan hubungan seksual berkisar antara 13-18 tahun (Seo, 2010).

Variabel jenis kelamin, usia pubertas, pengetahuan, sikap, status perkawinan orang tua, pola asuh orang tua, jumlah pacar, lama pertemuan dengan pacar dan paparan media elektronik dan media cetak berhubungan bermakna dengan perilaku seksual remaja. Pada analisis multivariat ditemukan bahwa jenis kelamin, pengetahuan, pola asuh orangtua dan jumlah pacar yang pernah dimiliki secara bersama-sama memengaruhi perilaku seksual (Nursal, 2007). Hasil analisa menunjukkan bahwa faktor-faktor yang berhubungan dengan sikap siswa SMA terhadap hubungan seksual adalah kecerdasan emosi, pengetahuan kesehatan reproduksi, peran orangtua dan teman sebaya, peran media massa (Tutwuri Prihatin 2007).

\section{METODE PENELITIAN}

Berdasarkan pendekatan penelitian, maka penelitian ini merupakan jenis penelitian dengan desain deskriptif kuantitatif. Penelitian ini menggunakan metode deskriptif yang bertujuan untuk menjelaskan serta meringkaskan berbagai kondisi, situasi, atau berbagai variabel yang timbul di masyarakat yang menjadi objek penelitian itu berdasarkan apa yang terjadi. Peneliti menggunakan metode deskriptif untuk melihat sebab-akibat antara variabel bebas (pola asuh orangtua) dengan variabel terikat (perilaku seksual remaja). Metode ini digunakan untuk meneliti pada populasi atau sampel tertentu, pengumpulan data menggunakan instrumen penelitian, analisis data bersifat kuantitatif/ statistik, dengan tujuan untuk menguji hipotesis yang telah ditetapkan. penelitian ini menggunakan pendekatan deskriptif kuantitatif untuk mengukur pengaruh pola asuh orangtua dengan perilaku seksual remaja di SMA Advent Martoba Pematang siantar. Populasi dalam penelitian ini adalah remaja Sekolah Menengah Atas Martoba Pematang siantar. Teknik pengambilan sampel yang 
akan digunakan dalam penelitian ini adalah purposive sampling.

\section{HASIL DAN PEMBAHASAN}

Tabel 1. Distribusi Persentase Usia \begin{tabular}{lll} 
Responden & & \\
\hline Usia & Responden & Persentase
\end{tabular}

\begin{tabular}{lll}
\hline 15 & 8 & $10.0 \%$ \\
16 & 19 & $23.4 \%$ \\
17 & 32 & $39.5 \%$ \\
18 & 22 & $27.1 \%$ \\
Total & 81 & $100 \%$ \\
\hline
\end{tabular}

Dari tabel 1. terlihat bahwa responden berusia 15 tahun adalah berjumlah 8 orang $(10,0 \%)$, responden berusia 16 tahun berjumlah 19 orang $(23,4 \%)$, responden yang berusia 17 tahun berjumlah 32 orang (39.5\%), dan responden yang berusia 18 tahun berjumlah 22 orang (27.1\%). Menurut Arikunto data ini menunjukkan bahwa responden dalam penelitian hampir setengah berusia 17 tahun $(39.5 \%)$.

Tabel 2. Distribusi Persentase Jenis Kelamin

\begin{tabular}{lcc}
\hline Jenis Kelamin & Responden & Persentase \\
\hline Laki-laki & 32 & $39.5 \%$ \\
Perempuan & 49 & $60,5 \%$ \\
Total & 81 & $100 \%$ \\
\hline
\end{tabular}

Dari tabel 2. didapati responden berjenis kelamin laki-laki berjumlah 32 orang (39.5\%) dan responden berjenis kelamin perempuan berjumlah $49(60.5 \%)$. Lalu diinterpretasikan berdasarkan persentase
Arikunto, maka responden dalam penelitian ini sebagian besar adalah perempuan $(60.5 \%)$.

Tabel 3. Pola Asuh Orangtua

\begin{tabular}{llc}
\hline No & Pola Asuh & Persentase \\
\hline 1 & Pola Asuh Demokratis & $91 \%$ \\
2 & Pola Asuh Permisif & $67,7 \%$ \\
3 & Pola Asuh Dtoriter & $69 \%$ \\
\hline
\end{tabular}

Dari tabel 3. didapati pola asuh orangtua yang tertinggi adalah pola asuh demokratis (91\%), nilai ini diinterpertasikan berdasarkan skala persentase Likert adalah sangat baik. Berikutnya pola asuh kedua tertinggi adalah pola asuh otoriter $(69 \%)$, nilai ini diinterpertasikan berdasarkan skala persentase Likert adalah baik. Pola asuh dengan persentase terendah adalah pola asuh permisif $(67,7 \%)$, nilai ini diinterpertasikan berdasarkan skala persentase Likert adalah baik. Hasil ini sesuai dengan penelitian Yovanny (2012) dengan responden berjumlah 89 orang di SMA Negeri X Kupang yang menyatakan bahwa sebagian besar responden mendapatkan pola asuh demokratis yaitu $52,81 \%$, pola asuh otoriter yaitu $33,71 \%$ sedangkan pola asuh orang tua permissif merupakan pola asuh orang tua yang paling sedikit didapat oleh responden yaitu $13,48 \%$.

Tabel 4. Perilaku Seksual Remaja

\begin{tabular}{llc}
\hline No & \multicolumn{1}{c}{ Pernyataan } & Persentase \\
\hline 1 & $\begin{array}{l}\text { Ketika berpacaran, pacar saya } \\
\text { memanggil saya dengan kata }\end{array}$ & $65 \%$ \\
2 & $\begin{array}{l}\text { sayang } \\
\text { Rasanya memandangi lawan } \\
\text { jenis yang disukai adalah hal } \\
\text { yang ingin selalu dilakukan } \\
\text { setiap hari }\end{array}$ & \\
\hline
\end{tabular}




\begin{tabular}{|c|c|c|}
\hline 3 & $\begin{array}{l}\text { Pacar saya selalu menatap saya } \\
\text { dengan mesra }\end{array}$ & $73 \%$ \\
\hline 4 & $\begin{array}{l}\text { Wajar bagi searang pria } \\
\text { menggandeng pacarnya saat } \\
\text { berjalan }\end{array}$ & $72 \%$ \\
\hline 5 & $\begin{array}{l}\text { Menyenangkan duduk berduaan } \\
\text { sambil memegang tangan pacar }\end{array}$ & $75 \%$ \\
\hline 6 & $\begin{array}{l}\text { Hal yang lumrah duduk sambil } \\
\text { memegang tangan pacar }\end{array}$ & $79 \%$ \\
\hline 7 & $\begin{array}{l}\text { Menyenangkan dapat berciuman } \\
\text { dengan pacar asal bukan di } \\
\text { tempat umum }\end{array}$ & $85 \%$ \\
\hline 8 & $\begin{array}{l}\text { Berciuman merupakan variasi } \\
\text { dalam berрасагап }\end{array}$ & $88 \%$ \\
\hline 乌 & $\begin{array}{l}\text { Asal bukan di tempat umum, } \\
\text { berpelukan dengan pacar akan } \\
\text { menyenangkan }\end{array}$ & $92 \%$ \\
\hline 10 & $\begin{array}{l}\text { Tidak masalah meraba alat } \\
\text { kelamin pacar asal masih diluar } \\
\text { pakaian }\end{array}$ & $97 \%$ \\
\hline$\|$ & $\begin{array}{l}\text { Menyenangkan untuk berduaan } \\
\text { di tempat yang tertutup, sambil } \\
\text { mengelus tubuh bagian atas } \\
\text { pacar di dalam pakaian }\end{array}$ & $97 \%$ \\
\hline 12 & $\begin{array}{l}\text { Hal yang lumrah saling } \\
\text { menempelkan alat kelamin asal } \\
\text { masih berpakaian lengkap }\end{array}$ & $98 \%$ \\
\hline 13 & $\begin{array}{l}\text { Hubungan seks perlu dilakukan } \\
\text { untuk dapat mengetahui } \\
\text { kemampuan seks masing- } \\
\text { masing }\end{array}$ & $98 \%$ \\
\hline 14 & $\begin{array}{l}\text { Hubungan seks dapat dilakukan, } \\
\text { asal sama-sama mau }\end{array}$ & $98 \%$ \\
\hline 15 & $\begin{array}{l}\text { Tidak perlu ragu untuk } \\
\text { berhubungan seks dengan pacar } \\
\text { sendiri, asal bisa semakin } \\
\text { mempererat cinta }\end{array}$ & $98 \%$ \\
\hline & Jumlah persentase rata-rata & $86 \%$ \\
\hline
\end{tabular}

Dari tabel 4. maka didapati gambaran perilaku seksual remaja adalah $86 \%$. Menurut skala persentase nilai Likert pada tabel 3, maka nilai tersebut adalah sangat baik, yang artinya hampir seluruh remaja tidak melakukan perilaku seksual. Hasil ini sesuai dengan penelitian Hargiyati (2016) dengan responden berjumlah 303 orang di SMA X Bandung dan tempat yaitu $70 \%$ remaja tidak melakukan perilaku seksual.

Untuk menjawab identifikasi masalah yang ketiga bagaimana hubungan pola asuh orangtua dengan perilaku seksual remaja data diolah menggunakan SPSS, maka data diolah dengan uji statistik. Sebelum menentukan uji, maka terlebih dahulu ditentukan apakah data berdistribusi normal atau tidak seperti terlihat pada tabel 5 .

Tabel 5. Uji Normalitas KolmogorovSmirnov

a. Test distribution is Normal.

b. Calculated from data.

\begin{tabular}{|c|c|c|}
\hline & & $\begin{array}{l}\text { Unstandardized } \\
\text { Residual }\end{array}$ \\
\hline \multirow[t]{2}{*}{$\mathrm{N}$} & & 81 \\
\hline & Mean & DE-7 \\
\hline \multirow[t]{3}{*}{$\begin{array}{l}\text { Normal } \\
\text { Parameters }{ }^{\mathrm{a}, \mathrm{b}}\end{array}$} & Std. & 19,97500222 \\
\hline & Deviation & 2 \\
\hline & Absolute & 134 \\
\hline Most Extreme & Pasitive & 134 \\
\hline Differences & Negative & -.116 \\
\hline \multirow{2}{*}{\multicolumn{2}{|c|}{$\begin{array}{l}\text { Kolmagarav-Smirnav Z } \\
\text { Asymp. Sig. (2-tailed) }\end{array}$}} & .521 \\
\hline & & , 949 \\
\hline
\end{tabular}

Dari Tabel 5. dapat dilihat hasil normalitas Kolmogorov Smirnov, maka dapat kita lihat asymp. Sig. (2-tailed) pola asuh orangtua terhadap perilaku seksual remaja $\mathrm{p}$-Value $=0.949$. Jika $\mathrm{p}-$ Value $>$ dari nilai signifikan (0.005) maka dinyatakan data berdistribusi normal. Jika p-Value > nilai signifikansi, maka data dikatakan berdistribusi normal. 
Tabel 6. Korelasi Pearson Pola Asuh Orangtua dan Perilaku Seksual Remaja

\begin{tabular}{|c|c|c|c|}
\hline & & $\begin{array}{c}\text { Pola } \\
\text { Asuh } \\
\text { Orang } \\
\text { Tua } \\
\end{array}$ & $\begin{array}{c}\text { Perilaku } \\
\text { Seksual } \\
\text { remaja }\end{array}$ \\
\hline \multirow{3}{*}{$\begin{array}{l}\text { Pola } \\
\text { Asuh } \\
\text { Orang } \\
\text { Tua }\end{array}$} & $\begin{array}{l}\text { Pearson } \\
\text { Correlation }\end{array}$ & 1 &,$- 861^{\star \star}$ \\
\hline & $\begin{array}{l}\text { Sig. }(2- \\
\text { tailed) }\end{array}$ & & ,000 \\
\hline & $\mathrm{N}$ & 81 & 81 \\
\hline \multirow{3}{*}{$\begin{array}{l}\text { Perilaku } \\
\text { Seksual } \\
\text { remaja }\end{array}$} & $\begin{array}{l}\text { Pearson } \\
\text { Correlation }\end{array}$ &,$- 861^{* \star}$ & 1 \\
\hline & $\begin{array}{l}\text { Sig. }(2- \\
\text { tailed) }\end{array}$ & ,000 & \\
\hline & $\mathrm{N}$ & 81 & 81 \\
\hline
\end{tabular}

Data pada tabel 6. mencari korelasi antara kedua variabel. Jika hasil > $\mathrm{r}$ maka dikatakan signifikan, $-0,861>\mathrm{r}(0,5)$, maka antara pola asuh orangtua dan perilaku seksual remaja adalah signifikan. Tanda (-) artinya hubungan bersifat tidak searah yang artinya jika nilai variabel bebas besar, variabel terikat semakin kecil, tanda $* *$ menunjukkan bahwa hubungan variabel kuat (Muhammad, 2009). Untuk melihat apakah terdapat hubungan antara pola asuh orangtua dengan perilaku seksual remaja maka dapat kita lihat nilai $p$-Value, jika p-Value lebih kecil dari 0,05 maka dikatakan terdapat hubungan. Jika p-Value lebih besar dari 0,05 maka dinyatakan tidak terdapat hubungan. $\mathrm{p}$-Value $=0,000$ maka $<$ dari 0,05 maka dapat disimpulkan bahwa terdapat hubungan antara pola asuh orangtua dengan perilaku seksual remaja.

Dari tabel 6. didapati nilai korelasi Pearson -0,861 jika nilai korelasi > r maka dikatakan korelasi signifikan. Jadi -0,861 $>\mathrm{r}(0,5)$ maka korelasinya antara pola asuh orang tua dengan perilaku seksual remaja signifikan dan korelasi tidak searah yang artinya semakin tinggi pola asuh orangtua maka semakin kecil perilaku seksual pada remaja. Terdapat tanda ** yang artinya hubungan pola asuh orangtua dengan perilaku seksual remaja adalah kuat.

\section{KESIMPULAN DAN SARAN}

Berdasarkan penelitian yang dilakukan dapat disimpulkan bahwa terdapat hubungan antara pola asuh orangtua dengan perilaku seksual remaja yang signifikan dengan hubungan yang kuat dan tidak searah. Diharapkan kepada guruguru pengajar, orang tua dan remaja untuk dapat membimbing anak-anak muda dalam mempertahankan perilaku baik mengenai seksual.

\section{DAFTAR PUSTAKA}

Arikunto. (1998). Prosedur penelitian. Jakarta: Rhineka Cipta

BKKBN. 2009.Remaja dan SPN (Seks Pra Nikah).www.bkkbn.go.id WebsDetailRubrik.phpMyID=518 .pdf. Diakses pada 17 Desember 2017

Casmini. (2007). Emotional Parenting. Yogyakarta: P_idea

Dariyo, Agoes (2011), Psikologi Perkembangan Anak Tiga Tahun Pertama. Bandung : PT. Refika Aditama.

Darling, N. (2005). Parenting style and its correlates. Journal ERIC DIGESTEDO-PS-99-3.

Darmawan. 2013. Metode Penelitian Kuantitatif. Bandung: Remaja Rosdakarya. 
Departemen Kesehatan RI. 2002. Modul Kesehatan Reproduksi Remaja. Jakarta:

Departemen Kesehatan RI. 2009. Pedoman Pelayanan Antenatal di Tingkat Pelayanan Dasar. Jakarta: Depkes RI.

Depkes RI. 2005. Lebih 1,2 Juta Remaja Indonesia Sudah Lakukan Seks Pranikah. http://karodalnet.blogspot.com/20 08/08/lebih-12-jutaremajaindonesia-sudah.html. Diakses 7 Januari 2018.

Djiwandono, S. (2008). Pendidikan Seks Keluarga. Jakarta. PT. Indeks

Green L.W.,Kreuter M.W., 2000. Health Promotion Planning An educational adn Environmental Approach. Maylield Publishing Company

Gunarsa, D. Singgih. (2007). Psikologi Remaja cet. 16, hlm. 109. Jakarta: Gunung Mulia.

Hargiyati, Hayati. (2016). Hubungan pola asuh orang tua dengan perilaku seks Pranikah pada remaja usia (15-18) tahun di sma x kabupaten bandung, Bandung

Hurlock, E. B. 1980. Adolescent Development, Fourth Edition. Tokyo: Mc GrawHill.

Irawati dan Prihyugiarto, I. 2005. FaktorFaktor Yang Mempengaruhi Sikap
Terhadap Perilaku Seksual Pria Nikah Pada Remaja Di Indonesia: BKKBN.

Kementerian Kesehatan (Kemenkes) [Indonesia], 2009. Yang Perlu Diketahui Petugas Kesehatan Tentang Kesehatan Reproduksi. Jakarta, Indonesia: Kemenkes

Masland, P.R. (2004). Apa yang ingin diketahui remaja tentang seks.Jakarta:Bumi Aksara

Muhammad, N. (2009). Pendekatan Statistika Modern untuk Ilmu Sosial. Jakarta Salemba Humanika

Mu'tadin, Z. (2002). Remaja dan rokok, www.e-psikologi.com Diambil Pada Tanggal 10 Desember 2011.

Nursalam. (2008). Metodologi Penelitian Ilmu Keperawatan. Jakarta: Salemba Medika.

Pawestri. (2013). Pengetahuan, Sikap dan perilaku remaja tentang seks pranikah, Semarang

Potter, P.A, Perry, A.G.Buku Ajar Fundamental Keperawatan : Konsep, Proses, dan Praktik.Edisi 4.Volume 2.Alih Bahasa : Renata Komalasari,dkk.Jakarta:EGC.200 5

Respati, W.S, dkk. (2006) Perbedaan konsep diri antara remaja akhir yang mempersepsi pola asuh orangtua authoritarian, permissive dan authoritatative. Jurnal Psikologi (Volume 4 Nomor 2) 
Rineka Cipta. Notoadmojo, S. (2001). Promosi Kesehatan : teori dan aplikasi. Jakarta: PT. Rineka Cipta.

Rumini S. dan Sundari S. 2004. Perkembangan Anak dan Remaja. Jakarta : PT Rineka Cipta.

Santrock, J.W. 2003. Adolescence : Perkembangan Remaja. Jakarta: Penerbit Erlangga. Alih bahasa oleh : Shinto B. A. dan S. Saragih.

Saputra, N. (2015), Cara menghitung kuesioner skala likert

Sarlito Wirawan Sarwono. 2010. Psikologi Remaja. Jakarta: PT. Raja Grafindo Persada.

Sarwono, S. (2011). Psikologi Remaja. Jakarta: PT. Raja Grafindo.

Sarwono, W.S. (2010).Psikologi Remaja. jakarta: PT. Raja Grafindo Persada.

Sarwono W.S. 2003. Psikologi Remaja. Jakarta: Grafindo Persada.

SDKI. 2007. Survey Dinas

Kesehatan.Indonesia

Sedarmayanti. (2011). Manajemen Sumber Daya Manusia, Reformasi Birokrasi dan Manajemen Pegawai Negeri Sipil (cetakan kelima). Bandung : PT Refika Aditama
Seo. 2010. Trend Seks Pranikah Remaja Indonesia. http://besteasyseo. blogspot.com (diakses pada tanggal 2 Desember 2017)

Soetjiningsih. (2004). Tumbuh Kembang Remaja dan Permasalahanya. Jakarta:

PT. Rhineka Cipta.

Sugihartono, dkk. (2007). Psikologi Pendidikan. Yogyakarta: UNY Press

Sugiyono (2010). Statistika Untuk Penelitian. Bandung : Alfabeta.

Sugiyono. 2012. Statistik untuk Penelitian. Bandung : Alfabeta

Sugiyono. 2011. Metode Penelitian Kuantitatif, Kualitatif dan R\&D. Bandung: Afabeta

Sugiyono. (2012). Memahami Penelitian Kualitatif'. Bandung ALFABETA

WHO. 2011. Aborsi Dalam Tinjauan Etika Kesehatan, Perspektif Islam, dan Hukum di Indonesia. Jurnal Biologi Fakultas Sains dan Teknologi UIN Maliki Malang, hal 2.

Yovanny, M. (2012). Hubungan antara pola asuh orang tua dengan perilaku seksual Siswa sma negeri 3 kota kupang, Kupang 